\title{
A DENSIDADE POÉTICA DA MARGEM: O LUGAR DE ONDE OS BRÔ MC'S EMITEM A SUA VOZ, O SEU CANTO
}

\section{THE POETIC DENSITY OF THE MARGIN: THE PLACE WHERE THE BRÔ MC'S SEND YOUR VOICE, YOUR SINGING}

\author{
Lays Emanuelle Viédes Lima ${ }^{1}$
}

\section{RESUMO:}

Brô MC's são protagonistas do primeiro grupo de rap indígena do Brasil. Seu lócus de enunciação situa-se entre as aldeias Jaguapiru e Bororó, no município de Dourados (MS), onde vivem com outras 15 mil pessoas. Esta comunicação propõe-se discutir a densidade poética da Margem, o lugar de existência desses seres humanos, que apesar de um discurso que os produz como corpos racializados, performatizam uma lógica outra, que vai de encontro com o mundo ocidentalizado. Para tanto, nos justificamos a partir da perspectiva teórica póscolonial, que se insere no âmbito dos Estudos Culturais e outras abordagens correlatas, tais como os estudos de Jorge Larrosa, "Tremores. Escritos sobre a experiência" (2016); Édouard Glissant, "Introdução a uma Poética da Diversidade" (2005); Homi Bhabha, "O Local da Cultura" (1998). 0 ponto de partida é articular interpretações com base nesses referenciais com a música "Eju Orendive", do rap indígena dos BRô MC's.

\section{PALAVRAS-CHAVE:}

Densidade poética. Margem. Linguagem. Práticas culturais. Experiência.

\section{ABSTRACT:}

Brô MC's are protagonists of the first indigenous rap group in Brazil. Its locus of enunciation is between the villages Jaguapiru and Bororó, in the municipality of Dourados (MS), where they live with another 15 thousand people. This communication proposes to discuss the poetic density of the Margin, the place of existence of these human beings, who despite a discourse that produces them as racialized bodies, performs a different logic, which goes against the Westernized world. To that end, we justify ourselves from the postcolonial theoretical perspective, which falls within the scope of Cultural Studies and other related approaches, such as Jorge Larrosa, "Tremors. Writings on Experience "(2016); Édouard Glissant, "Introduction to a Poetics of Diversity" (2005); Homi Bhabha, "The Location of Culture" (1998). The starting point is to articulate interpretations based on these references with the song "Eju Orendive", of indigenous rap of BRÔ MC's.

\section{KEY WORDS:}

Poetic Density. Margin. Language. Cultural practices. Experience.

1 Mestranda em Letras: Linguagem e Identidade pela Universidade Federal do Acre. Bolsista Capes Demanda Social; 
Pobre as concepções de corpos indígenas, alteridade, a densidade poética da margem e entre-lugar, o que se propõe com este artigo é o desejo de promover um diálogo entre as vozes da academia pela perspectiva teórica dos Estudos Culturais e as vozes da (com)posição musical Eju Orendive do grupo Brô MC's, em diálogos com esses sujeitos cindidos (CREPALDE, 2014), esses sujeitos que nos ensinam como lidar com as diferenças e semelhanças, aprendendo a usálas em processos de misturas e crioulização (GLISSANT, 2005).

Tendo como ponto de partida, articularinterpretações com bases nos referenciais escolhidos por nós com a música "Eju Orendive", acompanhando a desconstrução linguística do rap indígena dos Brô MC'S, com vozes que refletem nas (com) posições de uma coletividade que, a partir das próprias experiências e das experiências de seus antepassados, estão afirmando a vontade de viver a vida como relação - "relação com o mundo, com a linguagem, com o pensamento, com os outros, com nós mesmos, com o que se diz e o que se pensa, o que dizemos e o que pensamos, com o que somos e o que fazemos, com o que já estamos deixando de ser... mas também querem construir experiência" (LAROSSA, 2016, pp. 74-111).

A motivação que proporcionou o bordado dessa narrativa, germinou a partir da rememoração de experiências/ vivências na cidade de Dourados, Mato Grosso do Sul (entre os anos de 2014 até meados do ano de 2016), cidade marcada por violências de uma colonialidade que está representada na relação do Estado com as populações indígenas e que se expressa também na permanência da tutela e na negação de direitos constituídos, que como efeito, embaçam a vista e alteram a percepção, provocando uma espécie de delírio, uma adulteração dos dados da realidade exterior. Apesar disso, embora residindo meio a esse espaço tenso $\mathrm{e}$ 
frutífero ao mesmo tempo, foi possível "projetar no corpo o pensamento para que o sentido fosse pensado".

É em territórios de disputas e intercâmbios violentos, que delimitam as espacialidades (COLUCCI; SOUTO, 2011) e territorialidades da rodovia que corta as áreas indígenas de Dourados, em que os Guarani Kaiowá vivem seus espaços/ tempos, reordenam a relação com seus territórios produzem suas culturas, suas narrativas e lutam pela afirmação de um modo de vida em contextos de risco, opressão e violência. Nesses territórios fomos marcados pela observação da invisibilidade social que atravessavam tantos corpos, especificamente os corpos de índios/índias (sobre)viventes de um entorno hostil. Um entorno marcado pela presença de rodovias atravessando seus territórios ancestrais, pelo agronegócio da soja - com seus venenos, tratores, aviões, caminhões, armas, fazendeiros e jagunços assassinos - e do aparato estatal precarizando suas vidas, tentando exterminar seus corpos, eliminar suas vozes, suas humanidades.

Apesar de Dourados, ser o lugar onde "aquilo que ninguém merece", não deveria "acontecer a ninguém", acontece todo dia, é também lugar de contato, espaço em trânsito, "entre-lugar" que, permeado pela diversidade de leituras e vivências territoriais como indica Bhabha (2010), mutuamente se tencionam, se negam, se confluem e se recriam, expressando diferentes ritmos temporais na elaboração de novas respostas ao superar as tradicionais perspectivas que justificam a perpetuação do recíproco desconhecimento de um em relação ao "outro".

Eju Orendive do grupo Brô MC's chama atenção para tudo que o que fingimos não ver, para um genocídio/epistemicídio de mais de 500 anos, chama a nossa atenção para a luta de (sobre) vivência dos Guarani Kaiowá - e tantas outras comunidades humanas de índios/índias e de outras comunidades humanas exiladas/deslocadas 
em todo o mundo - tratado(a) s como corpos extermináveis, descartáveis?

Vozes censuradas? Destinos sociais subalternos? Seres livres para apodrecer e morrer? Humanidades aniquiladas?

Vivendo numa região tratada ou imaginada como periférica, onde vivem com outras 15 mil pessoas, essa mesma região (Dourados), considerada a mais populosa e violenta entre o Brasil e o Paraguai, é também conhecida como a região da Grande Dourados, uma das mais ricas do Mato Grosso do Sul, onde impera um entorno hostil marcado pela presença de rodovias que são comandadas pelo agronegócio e pelo aparato estatal que invisibilizam socialmente essas populações, uma vez que, segundo Silva (2014), os corpos e os territórios que essas pessoas habitam quase sempre já significam violência, por isso esses extermínios não desencadeiam uma crise ética.

Foi construída uma identidade aos indígenas, dada pela negação, tentativa de condená-los “à indiferença do não-tempo, não-espaço, nãopolítica, não-local", significantes da violência racial (diferença racial e cultural) que expõe a face violenta do Estado quando justifica "a decisão de matar algumas pessoas - a maioria (mas não apenas) composta de jovens de cor" (SILVA: 2014, p. 62).

Deslocando-se para o não-esperado, abalando o estereótipo do corpo estigmatizado pelo signo da exclusão social, renunciando doutrinações que são impostas pela lógica da colonialidade que negam seus corpos, suas linguagens, religiosidades, identidades, subjetividades, narrativas e seus saberes, tentando escapar da binária relação de poder/servidão das línguas, os Brô MC's emitem suas vozes, vozes dos discordantes na (com)posição da alteridade no entre-lugar Guarani Kaiowá.

Falam do lócus de existência, tekoha - que remete à construção de um modo de ser na interdependência com o 
espaço, ou seja, um teko (modo de ser, cultura) e um ha (lugar) de onde emana esse modo de ser, uma experiência regida por princípios universais, mas também por determinações culturais e ambientais (CREPALDE, 2015, p. 61) -, desde onde podem viver segundo seu modo de ser, território de coletividade no intercambiar de vidas humanas, não-humanas e sobre-humanas a partir de experiências autopoiéticas; territórios a partir dos quais se afirmas a margem dos estereótipos e classificações colonizatórias, dizem o que não são e o que não querem, afirmando a luta pela vida e vivenciando as mudanças e conflitos das transformações em devir.

Desde as reservas Jaguapiru e Bororó, onde vivem com outras 15 mil pessoas, na cidade de Dourados, Mato Grosso do Sul, que os jovens compositores do grupo Brô MC's (Bruno Veron, Clemerson Batista, Kelvin Peixoto, Charlie Peixoto e a backing vocal Dani Muniz) musicam palavras, em elaborações de significados que produzem no bojo da multiplicidade cultural de seu cotidiano, de suas crenças, de seus sonhos, de suas lutas: consciência do canto que enunciam e que ecoam vozes silenciadas pelos discursos hegemônicos em sua pretensão de promover a interpretação de culturas e línguas.

A escolha desses jovens é uma escolha que subverte os ordenamentos linguísticos hierarquizadores do conhecimento, saberes e corpos. Ao produzirem seus versos e suas rimas tecidas entre o português indígena/ afrodescendente/brasileiro e o guarani, quebram com o cativeiro do "significado inegociável" e se colocam em relação, relação de aceitação em dividir o lugar, concebendo o "Lugar" nas palavras de Édouard Glissant, como espaço/tempo de vivência dentro de um pensamento da errância, permitindo conceber o in-dizível dessa totalidade: "desvio que não é nem fuga nem renúncia, mas a arte nova 
do desatamento do mundo" (GLISSANT, 2005, p. 84). Nesse sentido, essa escolha implode a noção de identidade essencializada, única, homogênea, atávica, abrindo-a a relação com o Outro e à permuta com esse Outro, sem receios ou temores que "sua" identidade seja perturbada nem desnaturada (GLISSANT, 2014, p. 248).

$\begin{array}{ccc}\text { Essas } & \text { escolhas } & \text { são } \\ \text { experiências } & \text { geridas } & \text { por }\end{array}$ palavras que proporcionam encontros, que dão sentido aos seus corpos, corpos que, mais do que um conjunto de músculos, ossos, vísceras, reflexos e sensações, mesmo censurados, não cessam de dizer (COLLING; TEDESCHI, 2015). Aqui entendendo a semântica da palavra corpo, como sendo

uma força impossível de discernir, um continuum fora do alcance dos rótulos, das identidades fixas, das essências étnico-raciais, da imobilidade. Corpo como um processo infinito, uma pluralidade de múltiplas possibilidades e de devires. Corpo como um campo de lutas, disputas, tecido de narrativas e inscrições na carnalidade/ espiritualidade secular da vida (ALBUQUERQUE, 2017, p. 3).

Com suas músicas, sons, gestos, cores, os Brô MC's também promovem o direito à diferença e problematizam as dimensões dasviolências físicas, psicológicas e simbólicas contra suas existências, humanidades, culturas, contra seus saberes, agires e (a)fazeres enquanto sujeitos que agem sobre o mundo, pensando através do lugar que vivem e cantam.

0 gênero musical escolhido pelos jovens é o rap, uma escolha como forma de afirmação cosmopolítica (OLIVEIRA, 2016), transfiguram esteticamente as coisas que geralmente ignoramos ou desprezamos, produzindo-lhes novos sentidos, na construção de uma poética tecida nas vivências dos espaços sociais onde as culturas se encontram e se chocam, se entrelaçando umas com as outras, corporificadas pela experienciação de corpos e sentimentos nos intercâmbios 
de identidades em territórios da diferença colonial.

Eju Orendive, que significa "venha com nós/ venha com a gente", propõe ou pode ser interpretada como uma desarticulação frente à exacerbada tentativa de apagamento das diferenças, especialmente, quando enunciam de si para o mundo, quebrando a lógica fronteiriça de um mundo eurocentrado, assumindo-se conscientes do efeito do deslocamento que exercemsobrealíngua-"rastro/ resíduo" de uma luta que resiste contra o seu desaparecimento enquanto ancestralidade e corpos históricos seculares - compondo formas de re-significar contestando o mundo, hegemonias que, cotidianamente, ferem suas realidades e tentam empurrá-los ao assujeitamento, precarizando suas subjetividades, tentando apagar tudo que é "estranho" ao modelo ocidentalizado de cultura, língua, percepção estética, ética, referencial artístico, entre outros. Nessa direção, consideramos importante, refletir com Homi Bhabha, para quem o "'estranho' seja uma condição colonial e pós-colonial paradigmática, tem uma ressonância que pode ser ouvida distintamente ainda que de forma errática - em ficções que negociam os poderes da diferença cultural em uma gama de lugares transhistóricos" (BHABHA, 2010, p. 30).

Os Brô MC's, isto é, os Brothers, ao entoarem Eju Orendive, fazem das palavras um canto que conta suas histórias, posto que, em um mundo assimétrico e em meio às violências do "caos mundo" tratam de negociar suas permanências, sobrevivências, resistências, sabendo que cantar a história é algo que faz parte de suas formas de experiência cosmológica já que é por meio dos cantosreza que as conexões familiares mais importantes se fazem vivas, como também é o meio de entendimento do mundo e de seus modos de funcionamento. Ainda do ponto de vista cosmológico, é preciso lembrar o valor da palavra, tanto no que concerne à construção da 
pessoa quanto na edificação de mundos - seu uso, portanto, não deve ser excessivo ou dispendioso, mas sensível/poético já que sagrado, conector, distintivo e multiplicador (OLIVEIRA, 2016, p. 24).

E, cantando-contando suas histórias, vão interpretando o mundo em que vivem. Não o mundo que é narrado pelo cinema, pelo livro didático, pelo documentário, pela etnografia, pela novela, pelo teatro, pela literatura, pelo senso comum, mas sim, históriasrelatos do sofrimento de seu povo, da luta pela terra, do enfrentamento ao racismo, ao preconceito e à toda sorte de intolerâncias; enfrentamento aos problemas do cotidiano, herdados do contato e misturas com o colonizador, tais como o consumo de drogas e o alcoolismo. Nessas lutas, suas vozes bradam poderosos apelos e denúncias pelo cessar do genocídio, do homicídio e do suicídio, que se materializam pelas balas da ação e omissão do Estado que tenta calar suas falas, silenciar seus cantos e inviabilizar seus movimentos.
Suas histórias-relatos falam do "drama" e da violência do colonialismo e da colonialidade. Nelas, suas vozes bradam ecos multiplicáveis pelo fim do martírio, que é dolorosamente real frente ao conflito de forças desproporcionais.

0 engajamento social proposto por esses jovens reflete uma bioreflexividade narrativa, a partir da qual produzem "narrativas das cenas de sua própria história, que se configuram como algo sempre particular, contingente, aberto e quiçá inesgotável, [procurando] dar sentidoàs suas experiências, e nesse percurso, [construindo] outras representações de [suas próprias trajetórias de vida e de lutas]", nas palavras de Nogueira (2015), para quem, os domínios das Ciências Humanas ou nos campos da Educação e/ ou Artes podem nos ajudar a pensar sobre

o processo de poder se reinventar, visto que possibilita a identificação, dos processos desencadeados pelos estados de ser/estar no mundo e que emergem do vivido no mundo (...) 0 argumento baseia-se na 
tese de que a reconstrução das paisagens (sejam elas afetivas, físicas ou psíquicas) de experiências do sensível, permite (...) por um lado, escutar melhor 0 seu entorno, o seu lugar e a si mesmo e, por outro institui a possibilidade de outras e novas formas para pensar o mundo e suas relações (...) Isso se faz diante do processo de dizer, de narrar, (re)interpretar! Decorre daí a constatação da relação dialética entre a invenção de si e a ressignificação da experiência daquilo que nos acontece e de sua importância política estratégica (NOGUEIRA, 2015, p. 77).

Quando os rappers se lançam na proposta grupomusical Brô MC's, buscam apontar outras possibilidades de pensar e serem pensados, cantam (d)escrevendo escolhas, estratégias de comunicação com o mundo não-indígena, inclusive. Assim dizem os Brô, em Eju Orendive:

Aqui o meu rap não acabou / Aqui o meu rap está apenas começando / Eu faço por amor, escute faz favor / Não sei o que se passa na sua cabeça / O grau da sua maldade não sei o que você pensa/ Povo contra povo, não pode se matar / Levante sua cabeça / Chego e rimo o rap GUARANI e KAIOWA / Você não consegue me olhar / E se me olha não me ver / Por isso venha com nós / Aqui é o rap GUARANI que está chegando pra revolucionar / 0 tempo nos espera, e estamos chegando / Por isso Venha com Nós / Aldeia unida mostra a cara / Mostrando pra você o que a gente representa / Porque aqui tem índios sonhadores / Agora te pergunto, rapaz por que nós matamos e morremos? / Em cima desse fato a gente canta / Índio e índio se matando / Os brancos dando risada / Por isso estou aqui pra defender meu povo / Represento cada um / E por isso, meu povo Eju Orendive / Nós te chamamos pra revolucionar / Por isso Venha com Nós, nessa levada / Nós te chamamos pra revolucionar / Aldeia unida, mostra a cara.

$\mathrm{Na}$ resistência em um contexto que favorece mais a homogeneização dos seus modos de existir, os rappers dos Brô MC's buscam afirmar seus corpos-existências em palavras, letras e músicas, pois realizam uma espécie de mediação intercultural nos seus modos múltiplos de existência em uma perspectiva multilíngue de relação com seu 
entorno. Uma relação a partir da qual se misturam, traduzem e se traduzem. Tradução aqui pensada com um ato de criação, capaz de produzir sentidos novos; tradução que significa

não é apenas uma invenção limitada a equivalências maravilhosas entre dois sistemas de linguagem: ela também cria categorias e conceitos inéditos, revoluciona ordens estabelecidas, suas imagens são de profusão e raro silêncio, ela precipita a celeridade do espírito (...). Por efeito dos fluxos de tradução (entre outras transferências atuantes) os lugares do mundo se revelam a nós, tornam-se lugares-comuns, os quais não se congelam em receptáculos, mas abremse em cadinhos fervilhantes portadores de sentidos novos, nos quais a cada vez um pensamento do mundo se encontra, e prolonga e fecunda um pensamento do mundo (GLISSANT, 2014, pp. 141-142).

Partindo desse princípio, nos contagiamos com os Brô, com suas/nossas possibilidades de encontros/ contágios/misturas em todos os sentidos. Misturas essas que têm a ver com uma percepção ético-estética do assumir suas lutas como nossas lutas, suas causas como nossas causas. Ao ouvi-los, ritmando nossos corpos carentes de abraços, afetos e percepções outras; carentes de descobertas do que somos a partir de nossa própria capacidade de desvendar outras subjetividades, destruidoras/ reveladoras de nossos eus, também nos colocamos em marcha nesse traduzir e traduzir-se, cientes que somos do "aqui/lá", do "dentro/fora", do "local/global" que nos torna seres de um mundo que é um todo único de humanidades, não-humanidades e sobrehumanidades. Um mundo único que temos que lutar todos os dias para preservar e possibilitar um lugar para todos no espaço público que deve abrigar - sem distinções de raça, gênero ou classe - a igual/ diferente comunidade humana em respeitosa e equilibrada relação de intercâmbios e partilhas com os demais seres que habitam o planeta terra.

Os corpos em movimento, o ritmo, a letra, o som e todos os artefatos que envolvem 
Eju Oredive evidenciam a capacidade dos Brô de entrar e se movimentar no "campo vibrante de imantação" do qual nos fala Glissant, ou nessas zonas de vizinhança em que misturam as contrações de espaços, resultando nas inesperadas transferências progressivamente conquistadas entre totalidades de línguas, culturas e usos, ecoando os sentires de um mundo de tremor[es]. Nessas injunções, os Brô MC's são aqui percebidos na perspectiva glissaniana do conceito do "Todo-o-Mundo", um mundo em que "os seres humanos, e os animais e as paisagens, e as culturas e as espiritualidades se contaminam mutuamente". Inspirados nas leituras de Glissant, destacamos que o tremor não representa sinal de inabilidade, fragilidade, ou falta de algo, constituindose como a própria qualidade daquilo que se opõe ao brutal unívoco rígido do eu menos o outro (GLISSANT, 2014, pp. 81142).

Nos espaços da articulação de diferenças culturais e na emergência dos interstícios que as experiências intersubjetivas e coletivas, elaborações de estratégias de subjetivação (singular ou coletiva) dão início a novos signos de identidade - inovadores e contestadores em torno da própria ideia de sociedade, sendo, o interesse comunitário ou o valor cultural - negociados (BHABHA, 2010). Nas trilhas abertas pelas reflexões de Homi Bhabha, surge a categoria da negociação para entendermos o que significa o processo de tradução e transferência de sentido, locais de instâncias contraditórias que produzem lugares e objetivos híbridos (de luta em detrimento da destruição das polaridades negativas, neutralizações binárias, subalternas e conformistas). Nessa direção, ganha destaque a noção de cisão,

que constitui uma intrincada estratégia de defesa e diferenciação no discurso colonial (...) A cisão é então uma forma de incerteza e ansiedade enunciatórias e intelectuais que derivam do fato de que a recusa não é um mero princípio de negação ou elisão; ela é uma 
estratégia para a articulação de afirmações contraditórias e coevas da crença (...). 0 processo de recusa, mesmo ao negar a visibilidade da diferença, produz uma estratégia para a negociação dos saberes da diferenciação. Esses saberes dão sentido ao trauma e substituem a ausência de visibilidade. É precisamente essa vicissitude da ideia de cultura articulada no momento de sua rasura, que dá um não-sentido aos significados disciplinares da própria cultura - um nãosenso colonial, entretanto, que produz estratégias de autoridade e resistência culturais poderosas, embora ambivalentes (BHABHA, 2010, pp. 189-190).

Como sujeitos cindidos que são, os rappers do Brô, se enunciam como sujeitos culturais e políticos do entrelugar (SANTIAGO, 2000). São "sendo-no-mundo" que, ao escolherem um ritmo para entoar suas histórias e músicas, demonstram alteridade no juntar/misturar/ recriar de duas línguas em uma conversação baseada na horizontalidade entre aquele que diz e aquele que ouve. Tratase de um encontrar/produzir de línguas que bordeiam suas fronteiras e limiares em uma relação não repressora, não castradora em franca denúncia às tradicionais interdições dos ordenamentos dos sistemas lingüísticos. Nessa direção, nos convidam a olhar e ver, a caminhar com eles, a encerrar o tempo de espera no "tempo de agora" Guarani Kaiowá: Eju Orendive, venha com nós, venha com a gente.

\section{Referências}

ALBUQUERQUE, G. R. "Culturas, corpos e narrativas na diversidade social latino-americana: uma certa fronteira amazônica", In: ABEHACHE - Revista da Associação Brasileira de Hispanistas. Salvador (BA): ABH, 2017, pp. 39-60. Disponível em: https://goo.gl/KrA3ov.

BHABHA, H. 0 local da cultura. Trad. Myriam Ávila, Eliana Lourenço de Lima Reis, Gláucia Renate Gonçalves. Belo Horizonte: Ed. UFMG, 2010.

COLUCCI, D. G.; SOUTO, M. M. M. "Espacialidades eterritorialidades: conceituação e exemplificações", In: Geo-grafias artigos científicos. Belo Horizonte (MG), janeiro-junho, 2011, pp. 114-127. CREPALDE, A. A construção do significado do tekoha pelos Kaiowá do Mato Grosso do Sul. Porto Alegre (RS): UFRGS, 2014 (Tese de Doutorado). 
GLISSANT, E. Introdução a uma Poética da Diversidade. Trad. Enilce do Carmo Albergaria Rocha. Juiz de Fora (MG): Editora da UFJF, 2005.

GLISSANT, E. O Pensamento do Tremor - La cohée Du Lamentin. Trad. Enilce do Carmo Albergaria Rocha e Lucy Magalhães. Juiz de Fora (MG): Editora da UFJF/ Gallimard, 2014.

LAROSSA, J. Tremores: escritos sobre a experiência. Trad. Crisitna Antunes, João Wanderley Geraldi. 1. Ed., 2. reimp., Belo Horizonte: Autêntica Editora, 2016.

NOGUEIRA, S. V. Biorreflexividade Narrativa, In: COLLING, A. M.; TEDESCHI, L. A. (Orgs.). Dicionário Crítico de Gênero. Dourados (MS): Editora da UFGD, 2015. Pp. 75-77.

OLIVEIRA, L.. “BroMC's rap indígena: o pop e a constituição de fóruns cosmopolíticos na luta pela terra Guarani e Kaiowa", In: Revista do Programa de Pós-Graduação em Comunicação e Cultura da Escola de Comunicação da Universidade Federal do Rio de Janeiro, v. 19, n. 3, 2016, pp. 119220.

SANTIAGO, S. Uma literatura nos trópicos: ensaios sobre dependência cultural. 2. ed., Rio de Janeiro: Rocco, 2000.

SILVA, D. F. "Ninguém: direito, racialidade e violência", In: Meritum, v. 9, n.1, 2014, pp. 67117.

Data de recebimento: $18 / 12 / 2017$

Data de aceite: 26/12/2017 